\title{
Extended Release Gel Forming Solution Dosage Form
}

National Cancer Institute

\section{Source}

National Cancer Institute. Extended Release Gel Forming Solution Dosage Form. NCI

Thesaurus. Code C42935.

A solution that becomes gelatinous upon administration and is designed to release active and/or inert ingredient(s) at a controlled, prolonged rate so as to reduce dosing frequency. 